\section{Status of Bacterial Leaf Spot Disease of Anthurium in Trinidad and Characterization of Native Isolates of the Causal Organism, Acidovorax anthurii}

\author{
Annelle W.B. Holder, Winston Elibox, and Pathmanathan Umaharan ${ }^{1}$ \\ Department of Life Sciences, Faculty of Science and Technology, The \\ University of the West Indies, College Road, St. Augustine, Republic of \\ Trinidad and Tobago
}

Additional index words. bacterial foliar disease, tropical ornamental, biochemical characterization

Abstract. Bacterial leaf spot disease (BLS) of anthurium (Anthurium andraeanum Linden ex André), caused by Acidovorax anthurii has contributed to the decline of the anthurium industry in Trinidad along with bacterial blight disease caused by Xanthomonas axonopodis pv. dieffenbachiae. This study investigated the status of BLS 12 years after its first discovery in 10 commercial anthurium farms located in nine geographically isolated areas in Trinidad. The disease was prevalent in only four farms located in Arima, Carapo, Brazil, and Grand Couva, and was a problem only in the wet season. Severity of BLS showed a strong association with prevalence of BLS $(r=0.92 ; P<0.01)$ and rainfall $(r=0.64 ; P<0.05)$. Cultivar differences in susceptibility to BLS were manifested as variation in the severity of foliar symptoms in adult plants and as frequency of systemic infection and plant death in juvenile plants. The native $A$. anthurii isolates showed morphophysiological and biochemical properties similar to isolates reported from the French West Indies, but with some differences. Native isolates did not grow at $41^{\circ} \mathrm{C}$ or produce acid from arabinose, although some isolates produced acid from sucrose and mannitol. Two isolates were negative for urease activity, and one isolate did not elicit a hypersensitive reaction on the tobacco variety, 'Samsun NN'. The native $A$. anthurii isolates were positive for Tween 80 hydrolysis, negative for acid production from potassium tartrate, and variable for production of acid from ethanol. There were significant differences between isolate colony diameters on minimal media, potassium tartrate, mannitol, ethanol, and glycerol. However, growth in minimal media amended with glycerol produced the largest colony diameters (mean of $8.6 \mathrm{~mm}$ ). Although there were differences $(P<0.001)$ between the native isolates with respect to aggressiveness, significant cultivar $X$ isolate interaction was not observed. Isolates collected from different geographical regions did not differ in aggressiveness. These results show that there is greater variation in morphophysiology of $A$. anthurii isolates than previously reported.

Acidovorax anthurii (Gardan et al., 2000), the causal organism of BLS of anthurium (A. andraeanum Linden ex André), was first reported by Prior et al. (1985) in the French West Indies and later in Trinidad (Dilbar, 1992; Saddler et al., 1995). It is regarded as one of the major contributors to the demise of the anthurium industry in the Caribbean region (Saddler et al., 1995), along with bacterial blight disease caused by $X$. axonopodis pv. dieffenbachiae (Elibox and Umaharan, 2007). Cultural control methods have proven

Received for publication 16 Apr. 2014. Accepted for publication 24 Apr. 2015.

The authors wish to thank the staff of the Department of Life Sciences of the University of the West Indies at St. Augustine for their assistance in executing this study.

${ }^{1}$ To whom reprint requests should be addressed; e-mail pumaharan@sta.uwi.edu. to be inadequate in controlling BLS and it is generally believed that breeding for resistance is the only means of sustainable management of the disease. Since the first report in 1992, there have not been any follow-up studies to determine the prevalence and geographical distribution of BLS in Trinidad, although anecdotal reports indicate a widespread distribution and a significant negative impact on the industry. Furthermore, there have been no studies on the pathogenic variation of $A$. anthurii.

The causal agent of BLS enters the vascular system of anthurium leaves via natural openings (stomata and hydathodes) or wounds (Prior et al., 1985). Early foliar symptoms are small, angular, greasy spots on the lower surface of leaves near veins and leaf margins, and on spathes (Prior et al., 1985). These lesions develop rapidly resulting in large, black necrotic spots which become grey-black on older leaves often deforming the infected leaves (Prior et al., 1985). Necrotic spots are surrounded by greasy margins and narrow, bright chlorotic halos (Dilbar and Gosine, 2003; Prior et al., 1985). Under conditions of high humidity, bacterial slime oozes from the leaf margins. On spathe tissues, black or brown necrotic spots surrounded by violet halos usually develop (Dilbar and Gosine, 2003; Prior et al., 1985). Both leaf and spathe infections may progress into veins causing a soft rot with eventual abscission of the petiole and peduncle. Infections can become systemic resulting in a general yellowing of the entire leaf lamina and occurrence of typical black, necrotic lesions progressing from the leaf petioles into the major veins (Prior and Rott, 1989). Systemic infections lead to eventual plant death (Prior et al., 1985).

The $A$. anthurii isolates collected in the French West Indies have been characterized both morphophysiologically and biochemically (Gardan et al., 2000; Prior and Sunder, 1987; Prior and Rott, 1989; Saddler et al., 1995). All isolates were gram-negative motile rods $(0.2$ to $0.7 \times 1.0$ to $5.0 \mu \mathrm{m})$, with a single polar flagellum. They produced creamy white, circular, raised colonies with entire margins on Kelman's medium without tetrazolium chloride and amended with $1 \mathrm{~g} / \mathrm{L}$ yeast extract (KY), King's medium A (KMA), King's medium B (KMB) and yeast dextrose agar (YDA) media. Some isolates produced a brown diffusible pigment when grown at $41{ }^{\circ} \mathrm{C}$ on solid $\mathrm{KY}$ medium and all isolates elicited a hypersensitivity reaction on the tobacco variety, 'Samsun NN' (Prior et al., 1985). Furthermore, all isolates were strictly aerobic; positive for catalase; used arginine and asparagine as the sole source of carbon and nitrogen; produced hydrogen sulfide from cysteine; were tryptophan deaminase positive; showed urease activity; hydrolyzed cellulose; grew on YDA amended with $2 \% \mathrm{NaCl}$; produced acids from galactose, arabinose, glycerol; and used acetate, formiate, and citrate (Prior and Rott, 1989). Isolates were shown to be variable for production of acid from trehalose and glucose as well as for the utilization of D-tartrate and L-tartrate (Prior and Rott, 1989). They were positive for oxidase, nitrate reductase (Saddler et al., 1995), DL-5-aminobutyrate, D(-) tartrate, and azelate (Gardan et al., 2000). Schaad et al. (2001) reported that some Acidovorax species use D-glucose and ethanol.

All isolates from the French West Indies were also negative for production of fluorescent pigment on KMA or KMB and did not show turbidity after $10 \mathrm{~d}$ at $4{ }^{\circ} \mathrm{C}$ or $41^{\circ} \mathrm{C}$ in liquid KY medium (Prior et al., 1985). Furthermore, all isolates were negative for indole, levan, acetoin production; aesculin and casein hydrolysis; DNAse activity; pectinolysis; potato soft rot; growth on YDA amended with $5 \% \mathrm{NaCl}$; production of acid from inositol, sorbitol, mannose, sucrose, cellobiose, rhamnose; utilization of propionate and benzoate (Prior and Rott, 1989); arginine dihydrolase; starch hydrolysis; gelatin liquefaction (Saddler et al., 1995); trehalose; caprylate; D-ribose; D-glucose; N-acetylglucosamine; L-arginine; saccharose; inositol; sarcosine; itaconate; D-xylose; 
L-tryptophan; and mannitol (Gardan et al., 2000).

Dilbar (1992) observed that the A. anthurii isolates from Trinidad produced a brown pigment when grown on nutrient agar (NA) for $48 \mathrm{~h}$, but to date the morphological and biochemical variation or aggressiveness of isolates of A. anthurii have not been investigated. We do so in this paper as this information is important for breeding resistance to BLS in anthurium. We also report the status and distribution of A. anthurii in Trinidad 12 years after it was first reported, the extent of morphophysiological and biochemical variation and differences in aggressiveness among the native isolates. A more recent unpublished survey (2014) showed that all of the anthurium farms save one have collapsed due to the effects of either BLS, bacterial blight disease or both.

\section{Materials and Methods}

Sampling locations. The island of Trinidad experiences two seasons: a dry season (January to May; mean of $66.4 \mathrm{~mm}$ rainfall per month) and a wet season (June to December; mean of $220.4 \mathrm{~mm}$ rainfall per month). Ten commercial anthurium farms were surveyed for prevalence of BLS between June 2004 and June 2005. The farms varied in size from 0.12 to 6.5 ha and were concentrated largely in the valleys of the Northern and Central Mountain Ranges. The farms were located in nine geographical areas viz.: Santa Cruz (two farms), St. Joseph, Arima, Carapo, Brazil, Freeport, Gran Couva, Siparia and Erin (Table 1; Fig. 1). Kairi Blooms, Carapo; Phoenix Farm, Arima; and Spence, Brazil were located on a flat terrain while MBN Farms in St. Joseph was located on a steeply sloping terrain. The remaining farms were on gently sloping terrains. The anthurium cultivars were planted and maintained in shade houses ( $75 \%$ shade Saran) on beds of coconut husk in all farms. The average relative humidity, temperature, and light intensity under the shade houses were $83 \%$, $27.7{ }^{\circ} \mathrm{C}$, and $57 \mathrm{mmol} \cdot \mathrm{m}^{-2} \cdot \mathrm{s}^{-1}$, respectively. The mean annual rainfall data (50-year average) for each farm was obtained from the closest rain gauge maintained by the Water and Sewerage Authority of Trinidad and Tobago.

Anthurium cultivars. The 10 anthurium farms cultivated a range of elite cultivars, largely imported from the Netherlands, but also included cultivars from Hawaii and other European countries. The cultivars were grown mainly to supply cut flowers and leaves to the North American market. The exact identity of the cultivars was often not known by the farmers.

Prevalence and severity of BLS. The anthurium farms were surveyed for the prevalence of BLS and a questionnaire was used to obtain historical information regarding the prevalence and severity of the disease. Prevalence was coded as follows: $1=$ no occurrence of BLS to date, $2=$ BLS occurred in the past but is currently not present or it occurs sporadically and is of limited importance, and $3=$ the disease is endemic to the farming area and is of great importance. Severity was

Table 1. Prevalence ${ }^{z}$ and severity ${ }^{y}$ of bacterial leaf spot disease (BLS) of anthurium at various farm locations in Trinidad (2004/2005). Fifty year rainfall $(\mathrm{mm})$ average is given for each location.

\begin{tabular}{|c|c|c|c|c|c|c|}
\hline \multicolumn{4}{|c|}{ Farm } & \multicolumn{2}{|c|}{ BLS } & \multirow[b]{2}{*}{$\begin{array}{l}\text { Rainfall } \\
(\mathrm{mm} / \mathrm{yr})\end{array}$} \\
\hline Name & Location & $\begin{array}{l}\text { Size } \\
\text { (ha) }\end{array}$ & $\begin{array}{c}\text { Age } \\
\text { (years) }\end{array}$ & $\begin{array}{l}\text { Prevalence } \\
\text { index }\end{array}$ & $\begin{array}{l}\text { Severity } \\
\text { index }\end{array}$ & \\
\hline Kairi blooms & Carapo & 6.47 & 15 & 3 & 4 & $2,177.5$ \\
\hline Anandale & Erin & 0.81 & 11 & 2 & 1 & $2,127.9$ \\
\hline Gibson & Santa Cruz & 0.12 & 16 & 2 & 2 & $1,916.9$ \\
\hline Harrisingh & Siparia & 0.40 & 12 & 1 & 0 & $2,027.9$ \\
\hline Hutchinson & Gran Couva & 0.81 & 16 & 2 & 3 & $2,887.7$ \\
\hline Tropical blooms & Freeport & 1.62 & 10 & 2 & 1 & $1,972.0$ \\
\hline MBN Farms & St. Joseph & 1.42 & 14 & 1 & 0 & $2,098.8$ \\
\hline Phoenix Farms & Arima & 1.01 & 9 & 2 & 1 & $2,208.4$ \\
\hline Spence & Brazil & 0.40 & 12 & 3 & 4 & $2,620.5$ \\
\hline Sultan & Santa Cruz & 0.12 & 8 & 1 & 0 & $1,916.9$ \\
\hline
\end{tabular}

${ }^{\text {} P r e v a l e n c e ~ o f ~ B L S ~ b a s e d ~ o n ~} 1=$ farm has had no history of disease; 2 = BLS has occurred in the past, but currently is not present or occurs sporadically and is of limited importance; and $3=\mathrm{BLS}$ is endemic to the farming area and is of great importance.

${ }^{y}$ The severity of BLS based on $0=$ disease has never occurred at this farm; $1=$ leaf symptoms occur sporadically; 2 = disease is endemic, but only foliar symptoms have been observed; 3 = disease is endemic, but occasionally become epidemic; and $4=$ disease occurs at epidemic levels on a regular basis with significant plant loss.

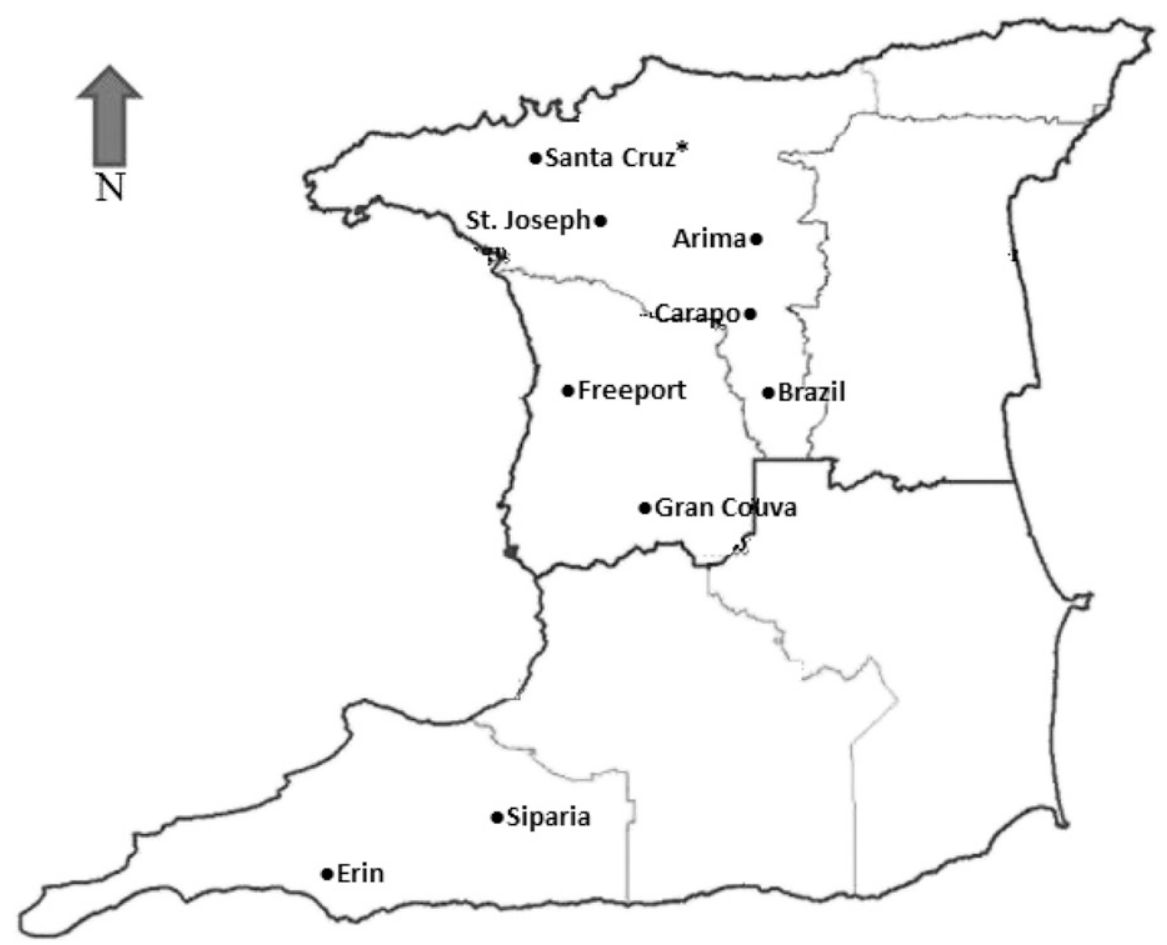

Fig. 1. Map of Trinidad indicating the 9 geographical locations of the 10 commercial anthurium farms in Trinidad. *There were two farms located in Santa Cruz.

coded as follows: $0=$ BLS has never been encountered historically by the farm; $1=$ the farm encounters leaf symptoms of BLS sporadically; $2=\mathrm{BLS}$ is endemic in the farm but only foliar symptoms have been observed; $3=$ BLS is endemic to the farm resulting in foliar symptoms which can occasionally become epidemic; and $4=$ BLS occurs at epidemic levels in the farm on a regular basis with significant plant loss.

Isolation and confirmation of pathogen. During the wet season of 2004, anthurium leaf or spathe samples showing typical symptoms of BLS were collected from five to 10 separate diseased plants from various parts of each of 4 anthurium farms (Kairi Blooms,
Phoenix Farms, Spence, and Hutchinson). The samples were placed in separate labeled clear plastic bags and transported on ice to the laboratory.

Each diseased leaf or spathe sample was surface disinfected with $70 \%$ ethanol and two $1-\mathrm{cm}^{2}$ pieces were dissected from the advancing margin of the lesion using a sterile scalpel, macerated in $1 \mathrm{~mL}$ of sterile distilled water and allowed to settle for $30 \mathrm{~min}$. A loopful of the suspension was then streaked onto freshly prepared NA plates and incubated for $48 \mathrm{~h}$ at $30^{\circ} \mathrm{C}$. A pure colony from each leaf or spathe sample was then replated onto a freshly prepared NA plate and incubated for $48 \mathrm{~h}$ at $30{ }^{\circ} \mathrm{C}$. Isolates were 
named and labeled with the name of the farm of origin and sample number (AV = Avey, $\mathrm{RJ}=$ Rajkumar, $\mathrm{SP}=$ Spence, $\mathrm{h}=$ Hutchinson) and stored as water suspensions at $25^{\circ} \mathrm{C}$.

Each isolate and a positive control (labeled $\mathrm{CAB}$ ) obtained from the Commonwealth Agricultural Bureaux, International (Surrey, UK) were streaked individually onto freshly prepared NA slants and incubated for $48 \mathrm{~h}$ at $30{ }^{\circ} \mathrm{C}$. The inoculum was diluted with sterile distilled water to $3.4 \times 10^{-8}$ colony-forming units $(\mathrm{CFU}) / \mathrm{mL}$ using a spectrophotometer set at $600 \mathrm{~nm}$. Pathogenicity tests were performed by syringe-injecting $0.1 \mathrm{~mL}$ of a bacterial suspension of each isolate into the petiole of stage-2 leaves (Elibox and Umaharan, 2007; Fukui et al., 1998) of susceptible anthurium cultivar, Safari, halfway between the base of the petiole and the leaf lamina. Leaves injected with distilled water served as negative controls and the experiment was performed twice. Inoculated leaves were incubated for $20 \mathrm{~d}$ at $30{ }^{\circ} \mathrm{C}$ in clear plastic bags containing moist tissue paper. Only 16 native isolates obtained from Kairi Blooms (AV isolates), Phoenix Farms (RJ isolates) and Spence ( $\mathrm{SP}$ isolates) and the $\mathrm{CAB}$ isolate elicited characteristic symptoms of BLS and pure cultures were reisolated from them. All 16 native isolates were confirmed as A. anthurii by the Commonwealth Agricultural Bureaux, International.

Morphophysiological and biochemical characterization of native A. anthurii isolates. All the native $A$. anthurii isolates plus the $\mathrm{CAB}$ isolate were evaluated for colony morphology, diameter, and color after $48 \mathrm{~h}$ growth at 30, 40, and $41{ }^{\circ} \mathrm{C}$ on NA and YBGA $(0.7 \%$ yeast extract, $0.7 \%$ bactopeptone, $0.7 \%$ glucose, $1.5 \%$ agar, $\mathrm{pH}$ 7.3). They were also checked for Gram staining; growth in minimal medium; oxidase, catalase, arginine dihydrolase, and nitrate reductase activity; Tween 80, gelatin and starch hydrolysis; levan production; motility; fluorescence on $\mathrm{KMB}$; polyhydroxy butyrate (PHB) inclusions; acid production on ethanol, sucrose, glucose, mannitol, inositol, glycerol, galactose, arabinose; growth on potassium tartrate media; and urea utilization (after $7 \mathrm{~d}$ of incubation at $30^{\circ} \mathrm{C}$ ) as described by Lelliott and Stead (1987). All isolates were also tested for production of hydrogen sulfide from cysteine as well as ability to cause rot on potato (Schaad et al., 2001). The experiments were performed according to a randomized complete block design with three replications. The $\mathrm{CAB}$ isolate was used as a positive control and an uninoculated tube of each medium was used as a negative control.

Tobacco hypersensitivity to BLS isolates was tested by syringe-injection of $0.1 \mathrm{~mL}$ of a 48-h-old bacterial suspension $\left(3 \times 10^{8} \mathrm{CFU} / \mathrm{mL}\right)$ of each isolate into the mesophyll of three fully expanded leaves of tobacco cultivar 'Samsun NN' (Lelliott and Stead, 1987). Sterile distilled water was used as a negative control. The experiment was arranged in a randomized complete block design with three replications. The plants were held in a greenhouse maintained at $29^{\circ} \mathrm{C}$ with light intensity of $22.6 \mathrm{~W} / \mathrm{m}^{2}$ and observed for $48 \mathrm{~h}$. Isolates that developed necrotic regions along the infiltrated leaf area with subsequent collapse were classified as positive and leaves that developed no necrosis were classified as negative for the test (Lelliott and Stead, 1987).

Aggressiveness test. Five leaf discs $(2.67 \mathrm{~cm}$ diameter) obtained from stage-4 leaves of anthurium cultivars 'Safari' and 'Tropical' were separately vacuum infiltrated ( $15 \mathrm{psi}, 5 \mathrm{~s})$ with inoculum $\left(6 \times 10^{8} \mathrm{CFU} / \mathrm{mL}\right)$ from each of 16 native bacterial isolates. The $\mathrm{CAB}$ isolate served as a positive control and sterile distilled water as negative control; all discs were held in a humidity chamber (Elibox and Umaharan, 2008; 2010). The experiment was arranged in a 2 (cultivars) $\times 18$ (inocula) factorial structure and replicated three times over time. The original infiltration area of each disc was traced onto clear plastic and transcribed onto brown paper. The area of the cutouts were determined using a leaf area meter $(\Delta \mathrm{T}$ Area Meter MK2 model, Delta-T Devices, England), and used as a covariate to correct the final lesion size. The discs were incubated at $30{ }^{\circ} \mathrm{C}$ for $5 \mathrm{~d}$ in plastic trays lined with two layers of moist paper towels and enclosed individually in clear polythene bags. Lesion size was measured after $5 \mathrm{~d}$ by tracing the infection spread area and determining the area of the cutouts using the leaf area meter. The degree of lesion expansion of each isolate was used as a measure of its aggressiveness.

Data analysis. Pearson's product moment correlation analysis (NCSS, 2001) was performed to determine the association between the mean total rainfall and the prevalence and severity of BLS as well as the association between prevalence and severity of BLS. One-way analyses of variance (ANOVAs; NCSS, 2001) were used to determine whether there were significant differences between isolates with respect to colony diameter in four nutritional (potassium tartrate, mannitol, ethanol and glycerol) media and minimal media. Where a difference was significant, a standard error, least significant difference, and a $\mathrm{CV}$ were calculated.

One-way ANOVA (NCSS, 2001) was used to test the significance between the $A$. anthurii isolates (17) with respect to aggressiveness measured as lesion area in $\mathrm{cm}^{2}$ after $5 \mathrm{~d}$ of incubation. A two-way ANOVA (NCSS, 2001) was performed to determine whether there were significant isolate $\times$ anthurium cultivar interaction. Pearson's product moment correlation was performed to determine the association between aggressiveness of the $A$. anthurii isolates (17) in the two susceptible anthurium cultivars ('Safari' and 'Tropical') as well as the associations between aggressiveness and mean colony diameter on the five nutritional media and between mean isolate aggressiveness per farm with mean rainfall, and symptom severity of the three farms.

\section{Results}

Prevalence and severity of BLS in Trinidad. Seven of the ten farms (located in Arima, Carapo, Brazil; Gran Couva, Freeport, Santa Cruz; and St. Joseph) reported having BLS at some time in their history. In this study, the disease was found in only 4 of the 10 farms located in Arima, Carapo, Brazil (foot hills of the Northern Mountain Range) and Gran Couva (Central Mountain Range), respectively (Fig. 1; Table 1). All farms reported that the disease was more problematic in the wet than the dry season and in young plants than in older plants.

Two farms had a BLS prevalence index of 3 (Kairi Blooms and Spence) while five of the farms had a prevalence index of 2 (Anandale, Gibson, Hutchinson, Tropical Blooms, and Phoenix Farms). Three farms (Harrisingh, MBN Farms, and Sultan) had a prevalence index of 1 (Table 1). Only two (Kairi Blooms and Spence) of the seven farms that had experienced BLS indicated that the disease was endemic to the area with recurring epidemics (severity index of 4). One farm (Hutchinson) reported that BLS is endemic resulting in foliar symptoms which can occasionally become epidemic (severity index of 3). Gibson farm of Santa Cruz indicated that the disease is endemic, but only foliar symptoms have been observed (severity index of 2). Three farms viz. Anandale (Erin), Tropical Blooms (Freeport), and Phoenix Farms (Arima) reported that they only encounter leaf symptoms of BLS sporadically (severity index of 1). The farms in which BLS was reported as endemic were located in various geographical regions, but farms where it occurred in epidemic proportions, resulting in both foliar and systemic symptoms and plant death, only occurred in the Central and Northern Mountain Ranges of Trinidad.

All seven farms with a history of BLS indicated that the disease mainly affected the foliage, but three farms (Kairi Blooms, Hutchinson, and Spence) reported higher incidences of systemic infection and death, particularly in young susceptible anthurium plants. Kairi Blooms reported the disease to be very severe when young plants were planted on beds of newly shredded coconut fiber. Only one farm (Kairi Blooms) reported that the disease was also a problem in older plants.

Average annual rainfall ranged from $1916.9 \mathrm{~mm}$ at Gibson and Sultan farms in Santa Cruz to $2887.7 \mathrm{~mm}$ in Hutchinson farm in Gran Couva (Table 1). The general mean was $2195.5 \mathrm{~mm}$. Prevalence of BLS was not correlated with rainfall $(r=0.45 ; P>0.05)$, but severity of BLS was correlated with rainfall $(r=0.64 ; P<0.05)$. Prevalence showed a strong association with severity $(r=0.92 ; P<0.01)$.

Biochemical/morphophysiological characterization of 16 pathogenic A. anthurii isolates. Like the $\mathrm{CAB}$ isolate, the colonies of all 16 native $A$. anthurii isolates were gramnegative and off-white in color on NA medium, but became cream colored on YBGA medium. Colonies were circular in shape with a diameter ranging from 0.5 to $1.5 \mathrm{~mm}$ after $48 \mathrm{~h}$ incubation at $30^{\circ} \mathrm{C}$. No isolate was able to grow at 40 and $41{ }^{\circ} \mathrm{C}$ when incubated on NA and YBGA media for $48 \mathrm{~h}$. Cells of all isolates were motile by means of a single polar flagellum.

All 16 native $A$. anthurii isolates and CAB were able to grow in minimal media and were 
also found to be positive for oxidase, catalase, Tween 80 hydrolysis, PHB inclusions, nitrate reductase, production of hydrogen sulfide from cysteine, but negative for arginine dihydrolase activity, gelatin hydrolysis, starch hydrolysis, potato rotting, levan production, and fluorescence on KMB medium. All isolates except two (SP1 and AV5) were positive for urease activity after $7 \mathrm{~d}$ incubation. All isolates except RJ9 elicited a hypersensitive reaction on tobacco variety, 'Samsun NN'. Two isolates (AV0 and AV9) produced acid from sucrose and glucose and these two isolates in addition to AV4 produced acid from mannitol. All isolates except AV0, SP1, AV3, and AV5 produced acid from ethanol. All native isolates and $\mathrm{CAB}$ produced acid from glycerol and galactose but no isolate (including $\mathrm{CAB}$ ) produced acid from inositol, potassium tartrate, and arabinose.

It was difficult to determine utilization of different nutritional media since all 17 isolates grew in minimal media. However, there were significant differences $(P<0.001)$ between isolates with respect to colony diameter in four nutritional (potassium tartrate, mannitol, ethanol, and glycerol) and minimal media (Table 2). RJ3 had the largest colony diameter on minimal media $(3.33 \mathrm{~mm})$, whereas AV7 had the smallest. AV5 had the smallest colony diameter $(1.83 \mathrm{~mm})$ on potassium tartrate, whereas, RJ3 had the largest $(8.67 \mathrm{~mm})$. AV5 had the smallest diameter on mannitol $(2.50 \mathrm{~mm})$ whereas $\mathrm{CAB}$ had the largest $(9.67 \mathrm{~mm})$. With regard to ethanol, AV5 had the smallest colony diameter $(1.67 \mathrm{~mm})$, whereas RJ0 and AV8 had the largest $(6.67 \mathrm{~mm})$. All isolates except AV7 had the largest colony diameters on glycerol (range of $4.33 \mathrm{~mm}$ for RJ9 to $9.67 \mathrm{~mm}$ for $\mathrm{CAB}$ ). Average colony diameter of $A$. anthurii isolates collected from Arima (RJ isolates) on different media were larger than isolates from Carapo (AV isolates) and isolates from Brazil (SP isolates) (Table 2).

Aggressiveness. There were significant differences in aggressiveness among the 17 isolates tested $(P<0.001)$. Mean lesion size ranged from $1.76 \mathrm{~cm}^{2}$ for isolate $S P 1$ to $3.46 \mathrm{~cm}^{2}$ for isolate AV3, with a mean of $2.94 \mathrm{~cm}^{2}$ for all the isolates (Table 2). Average lesion size of $A$. anthurii isolates collected from Kairi Blooms, Carapo (AV isolates; $3.1 \mathrm{~cm}^{2}$ ) were larger than those obtained from Phoenix Farms, Arima (RJ isolates; $2.9 \mathrm{~cm}^{2}$ ) and Spence, Brazil (SP isolates; $2.3 \mathrm{~cm}^{2}$ ) (Table 2). Despite the small standard error for lesion size $(0.080)$, the isolate $\times$ cultivar interaction was not significant $(P>0.05)$. Furthermore, the correlation between lesion sizes produced by the $A$. anthurii isolates on 'Safari' and 'Tropical' was large and significant $(r=0.94, P<0.01)$. Aggressiveness was not correlated $(P>0.05)$ with mean colony diameter on the five nutritional media and symptom severity.

\section{Discussion}

The survey showed that BLS was not ubiquitous throughout Trinidad but had a rather skewed distribution favoring the high rainfall areas. Evidence for this came from both the disease survey of farms as well as from the information on prevalence and severity collected from each farm based on the disease history. Pathogenic isolates of $A$. anthurii were collected from only three of ten existing commercial farms surveyed at the time of the study. These three farms are found in geographic locations associated with high rainfall in Trinidad. Furthermore, severity of BLS was strongly associated with high rainfall locations and was particularly severe in the rainy seasons. These suggest that the disease is more problematic in wet and humid parts of Trinidad. The study also found that prevalence of BLS was only weakly associated with rainfall $(r=0.45$; $P>0.05)$, suggesting that prevalence of BLS may perhaps be determined by factors such as contaminated planting material, contaminated soil or movement of farm personnel and visitors (Nishijima, 1989; Prior et al. 1985). Since all the commercial farms practiced strict sanitation practices where the diseased leaves are removed on a daily basis, it was difficult to determine the prevalence and severity at the time of the survey. A more recent unpublished survey performed in 2014 showed that anthurium cultivation in these farms, except for one (Kairi Blooms), has ceased due to BLS, bacterial blight disease, or both.

The 2004/2005 farmer survey showed that BLS occurred in epidemic proportions (resulting in both foliar and systemic symptoms) in central and northern areas of Trinidad. Dilbar (1992) also found that BLS was more prevalent in the north east of Trinidad where the three farms from which verified A. anthurii were isolated are located (Arima, Carapo, and Brazil; Fig. 1), and where annual rainfall is high. The farm (Kairi Blooms) that reported the most severe losses from BLS was located in Carapo, at the foothills of the Northern Mountain Range. Prior and Sunder (1987) also reported that dissemination of BLS was through water droplets splashing onto leaf surfaces which supports the observation in this study that the disease is more prevalent in areas of highest rainfall.

Of the 16 pathogenic isolates of $A$. anthurii collected in anthurium farms in Trinidad, all but one produced a hypersensitive reaction on tobacco. Although RJ9 did not produce a hypersensitive reaction, it was positive for pathogenicity in all host inoculation tests and showed morphophysiological and biochemical characteristics typical of $A$. anthurii. It is postulated that this isolate may be a mutant for the gene eliciting hypersensitivity in tobacco. All

Table 2. Mean colony diameter $(\mathrm{mm})$ on five media viz. minimal medium, potassium tartrate, mannitol, ethanol and glycerol for 16 native pathogenic isolates of Acidovorax anthurii and the positive $\mathrm{CAB}$ isolate, hypersensitivity reaction on tobacco variety 'Samsun NN' and mean lesion size elicited by the 16 native pathogenic isolates and the $\mathrm{CAB}$ isolate on leaf discs $(2.67 \mathrm{~cm}$ diameter) of two susceptible anthurium cultivars (Safari and Tropical) $5 \mathrm{~d}$ after inoculation.

\begin{tabular}{|c|c|c|c|c|c|c|c|c|}
\hline Isolate & $\begin{array}{l}\text { Location } \\
\text { collected }\end{array}$ & $\begin{array}{c}\text { Minimal } \\
\text { media }\end{array}$ & $\begin{array}{c}\text { Potassium } \\
\text { tartrate }\end{array}$ & Mannitol & Ethanol & Glycerol & $\begin{array}{l}\text { Hypersensitivity } \\
\text { reaction }\end{array}$ & $\begin{array}{l}\text { Mean lesion } \\
\text { area }\left(\mathrm{cm}^{2}\right)\end{array}$ \\
\hline AV0 & Carapo & 2.17 & 3.67 & 4.00 & 2.67 & 5.83 & + & 3.39 \\
\hline SP1 & Brazil & 1.67 & 3.67 & 4.00 & 2.17 & 5.67 & + & 1.76 \\
\hline SP2 & Brazil & 1.67 & 4.33 & 3.50 & 3.17 & 5.33 & + & 2.91 \\
\hline RJ0 & Arima & 2.67 & 5.00 & 4.00 & 6.67 & 9.00 & + & 3.28 \\
\hline AV9 & Carapo & 2.67 & 6.33 & 7.00 & 3.83 & 9.33 & + & 2.60 \\
\hline AV5 & Carapo & 2.00 & 1.83 & 2.50 & 1.67 & 4.5 & + & 3.28 \\
\hline RJ3 & Arima & 3.33 & 8.67 & 4.00 & 6.50 & 9.33 & + & 2.36 \\
\hline AV2 & Carapo & 2.33 & 6.00 & 6.00 & 5.00 & 8.33 & + & 2.85 \\
\hline AV1 & Carapo & 2.67 & 7.00 & 4.00 & 5.17 & 9.00 & + & 3.33 \\
\hline AV6 & Carapo & 2.00 & 4.33 & 3.33 & 3.83 & 5.17 & + & 3.16 \\
\hline CAB & Positive control & 3.00 & 4.67 & 9.67 & 6.50 & 9.67 & + & 2.80 \\
\hline AV7 & Carapo & 1.33 & 5.67 & 3.00 & 3.17 & 4.67 & + & 3.14 \\
\hline $\mathrm{CV} \%$ & - & 6.1 & 6.8 & 7.4 & 7.1 & 8.6 & - & 12.1 \\
\hline
\end{tabular}


the isolates of $A$. anthurii evaluated in the French West Indies (Gardan et al., 2000) produced a hypersensitive reaction on tobacco.

Like the positive control (CAB isolate), all native isolates of $A$. anthurii displayed morphological and biochemical properties that were typical of the pathogen (Dilbar, 1992; Gardan et al., 2000; Prior and Rott, 1989; Prior and Sunder, 1987; Prior et al., 1985; Saddler et al., 1995; Schaad et al., 2001) with some exceptions. Although all the isolates characterized from the French West Indies were able to grow at $41{ }^{\circ} \mathrm{C}$ (Prior et al., 1985 ), neither the native isolates nor the $\mathrm{CAB}$ isolate grew at that temperature. Two native isolates (SP1 and AV5) were consistently negative for urease utilization after $7 \mathrm{~d}$ incubation, in contrast to the observations of Prior and Rott (1989). Isolates AV0 and AV9 produced acid from sucrose and, in addition, AV4 produced acid from mannitol. This is in variance with the results of Prior and Rott (1989) and Gardan et al. (2000). Like the results obtained by Prior and Rott (1989), the Trinidad native isolates of $A$. anthurii were variable for acid production from glucose. Unlike the results of Prior and Rott (1989), none of the Trinidad native isolates nor $\mathrm{CAB}$ produced acid from arabinose. These results further indicate that there is wide variation among the native $A$. anthurii in Trinidad and that all or some isolates have some biochemical properties that are not typical of hitherto reported $A$. Anthurii isolates. In these respects, the native $A$. anthurii isolates from Trinidad are more variable than those reported from the French West Indies. These biochemical inconsistencies were independent of geographical locations where the isolates were collected.

This study provided further characterizations of $A$. anthurii. All native isolates were found to be positive for Tween 80 hydrolysis and negative for acid production from potassium tartrate. Furthermore, some Trinidad native isolates produced acid from ethanol. This latter property was previously reported for other Acidovorax species by Schaad et al. (2001) but not for A. anthurii.

Based on this study, it was difficult to determine utilization of various energy sources (potassium tartrate, mannitol, ethanol, and glycerol) since all the native $A$. anthurii isolates and $\mathrm{CAB}$ grew on minimal media. However, based on colony diameter, glycerol was found to be the best nutritional source for $A$. anthurii among the four energy sources. When grown in the four different nutritional media and minimal media, the native isolates produced colony diameters that were significantly different $(P<0.05)$, indicating differences among native $A$. anthurii isolates in Trinidad. Average colony diameter of $A$. anthurii isolates collected from Arima (RJ isolates) were larger on different media than isolates from Carapo (AV isolates) which was followed by isolates from Brazil (SP isolates). However, mean isolate colony diameter on the five nutritional media was not associated with aggressiveness $(r=-0.26$ to $-0.06 ; P>0.05)$. This study also showed that there were differences in aggressiveness of $A$. anthurii Trinidad isolates, but aggressiveness was not associated with any particular geographic location where the isolates were collected.

In conclusion, this study showed that commercial cultivation of elite anthuriums originating largely from the Netherlands was performed in 10 farms of varying sizes $(0.12$ $6.5 \mathrm{ha}$ ) that were located in nine geographical regions in Trinidad. Seven farms reported having BLS at some time in their history, but at the time of this study, the disease was restricted to only four farms located in four geographical regions viz. Arima, Carapo, Brazil, and Grand Couva. At those farms, BLS was reported to be more problematic in the wet than the dry season and in young plants than in old plants. Two farms (Kairi Blooms and Spence) indicated that BLS is endemic to the farming areas and is of great importance (prevalence index of 3), resulting in recurring epidemics with significant plant loss (severity index of 4). Severity of BLS was associated $(P<0.05)$ with prevalence of $\operatorname{BLS}(r=0.92)$ and rainfall $(r=0.64)$ but this study suggests that there may be other microclimatic conditions that affect aggressiveness of BLS as aggressiveness was not associated with the geographic location where isolates were collected. Isolate AV3 was the most aggressive isolate. The Trinidad native $A$. anthurii isolates were found to be similar morphophysiologically and biochemically to the isolates originating in the French West Indies, except that the native isolates did not grow at $41{ }^{\circ} \mathrm{C}$, were not able to produce acid from arabinose, and only some produced acid from sucrose and mannitol. Novel characterizations showed that native $A$. anthurii are positive for Tween 80 hydrolysis, negative for acid production from potassium tartrate, and variable for production of acid from ethanol. Glycerol was found to be the best energy source for culturing $A$. anthurii; however, the pathogen is able to grow in minimal media albeit at a slower rate. Anthurium cultivars 'Safari' and 'Tropical' were found to be equally susceptible to BLS.

\section{Literature Cited}

Dilbar, A. 1992. Studies on a new bacterial disease and other diseases of anthurium in Trinidad. Univ. West Indies, St. Augustine, Trinidad. MSc Diss.

Dilbar, A. and G. Gosine. 2003. Evaluation of susceptibility of anthurium hybrids to pseudomonas blight (Acidovorax anthurii sp.) and anthurium bacterial blight (Xanthomonas campestris pv. dieffenbachiae). CARAPHIN, IICA 23:4-6.

Elibox, W. and P. Umaharan. 2007. A green fluorescent protein-based screening method for identification of resistance in anthurium to systemic infection by Xanthomonas axonopodis pv. dieffenbachiae. Plant Pathol. 56(5):819-827.

Elibox, W. and P. Umaharan. 2008. A quantitative screening method for the detection of foliar resistance to Xanthomonas axonopodis pv. dieffenbachiae in anthurium. Eur. J. Plant Pathol. 121:35-42.

Elibox, W. and P. Umaharan. 2010. Inheritance of resistance to foliar infection by Xanthomonas axonopodis pv. dieffenbachiae in anthurium. Plant Dis. 94:1243-1247.

Fukui, H., A.M. Alvarez, and R. Fukui. 1998. Differential susceptibility of anthurium cultivars to bacterial blight in foliar and systemic infection phases. Plant Dis. 82:800-806.

Gardan, L., C. Douga, P. Prior, M. Gillis, and G.S Saddler. 2000. Acidovorax anthurii sp., a new phytopathogenic bacterium which causes bacterial leaf-spot of anthurium. Intl. J. Syst. Evol. Microbiol. 50:235-246.

Lelliott, R.A. and D.E. Stead. 1987. Methods in plant pathology 2. Methods for diagnosis of bacterial diseases in plants. Blackwell Scientific Publications, Oxford, UK.

NCSS. 2001. Number Crunching Statistical System. NCSS, Kaysville, UT

Nishijima, W.T. 1989. Current anthurium blight control recommendations, p. 7-9. In: J.A. Fernandez and W.T. Nishijima (eds.). Proc. 2nd Anthurium Blight Conf. HITAHR, Univ. Hawaii, Honolulu, HI.

Prior, P., B. Hostachy, P. Sunder, and P. Rott. 1985. Bacterial blight $(X$. campestris pv. dieffenbachiae) and bacterial leaf spot (Pseudomonas sp.) of anthurium in the French West Indies. Agron. Trop. 42:61-68.

Prior, P. and P. Rott. 1989. Bacterial leaf spot of anthurium (Anthurium spp.) caused by a Pseudomonas sp. in the French West Indies. J. Phytopathol. 124:215-224.

Prior, P. and P. Sunder. 1987. Les maladies bacteriennes de l'anthurium. P.H.M. Rev. Hort. 277.

Saddler, G.S., E.B. O'Grady, and J.A. Spence. 1995. Characterization of a pseudomonad-like bacterium pathogenic for Anthurium species. EPPO Bul. 25:211-217.

Schaad, N.W., J.B. Jones, and W. Chun. 2001. Laboratory guide for identification of plant pathogenic bacteria, 3rd ed. APS Press, St. Paul, MN 